\title{
GEOTURISMO NAS QUEDAS D’ÁGUA DO MUNICÍPIO DE INDIANÓPOLIS
}

\author{
Geotourism Waterfalls in Indianapolis County \\ Lilian Carla Moreira Bento* \\ Sílvio Carlos Rodrigues**
}

\begin{abstract}
Resumo
No Triângulo Mineiro se encontram raros e belos exemplares do patrimônio natural abiótico, como as quedas d'água de Indianópolis. Como este município é reconhecido pela variedade e beleza cênica de suas quedas, o objetivo geral deste trabalho foi identificar o potencial destes locais para a prática do geoturismo. Para atingir os objetivos propostos efetuou-se, em linhas gerais, revisão bibliográfica pertinente ao tema, trabalhos de campo ao longo dos cursos d'água com quedas e trabalhos de gabinete. A partir desta metodologia foram mapeadas 20 quedas no município de Indianópolis, todas com uma beleza e valor singulares, expondo em variados tamanhos unidades litológicas que permitem o entendimento da história geológica da região, bem como a identificação de processos geomorfológicos ativos na evolução e esculturação das quedas. Concluímos que é grande o potencial geoturístico das quedas d'água de Indianópolis, principalmente do Salto do Mirandão, Salto de Furnas e Saltinho Santo Antônio, no entanto, para que o município possa realmente implantar o geoturismo, usufruindo dos seus benefícios, é necessário proceder ao planejamento turístico e criar políticas públicas que regulamentem a atividade.
\end{abstract}

Palavras-chave: Turismo alternativo, geodiversidade, sustentabilidade, geoconservação, Indianópolis.

\begin{abstract}
In the Triângulo Mineiro area are rare and beautiful examples of abiotic natural heritage, such as waterfalls in Indianapolis County. This county is recognized by the variety and scenic beauty of the falls, so, the general aim of this study was to identify the potential of these sites to practice geotourism. To achieve the proposed goals, three kinds of activities were done: revision of relevant literature, field work along the watercourses and falls and cabinet research. Following the methodology 20 falls have been mapped in the city of Indianapolis, all with a natural beauty and value, showing rock units in various sizes that allow the understanding of the geological history of the region as well as the identification of active geomorphological processes in the evolution of waterfalls. We conclude that there is huge geotouristic potential in the Indianapolis waterfalls, mainly Mirandão, Furnas and San Antonio falls. However if the municipality actually wants to performe geotourism activities, enjoying its benefits, it is necessary to make tourism planning and creating public policies that regulate the activity.
\end{abstract}

Key words: Alternative tourism, geodiversity, sustainability, geoconservation, Indianópolis County.

\section{Resumen}

En el Triángulo Mineiro se encuentran raros y bellos ejemplares de patrimonio natural abiótico, como las cascadas de Indianópolis. Como este município es reconocido por las hermosas y variadas cascadas, el objetivo general de este trabajo fue indentificar el potencial de estos lugares para la implementación del geotursimo. Para poder lograr los objetivos propuestos se efectúo, en líneas generales, la revisión bibliográfica pertinente para este tema, trabajos de campo a lo largo de los cursos de agua con cascadas y trabajos de laboratorio. A partir de esta metodologia fueron mapeados 20 cascadas del municipio de Indianópolis, todas com una belleza y valor singular, en unidades litológicas de variados tamaños que permiten el entendimiento de la historia geológica de la región, como así también, la identificación de los procesos geomorfológicos activos en la evolución y modelación de las cascadas. Concluimos que es grande el potencial geoturístico de las cascadas de Indianópolis, principalmente Salto do Mirandão, Salto de Furnas y Saltinho Santo Antônio. Sin embargo, para que el municipio pueda realmente llevar a cabo el geoturismo, disfrutando de sus benefícios, es necesario realizar la planificación turística y crear políticas públicas que regulen las actividades.

Palabras clave: Turismo alternativo, geodiversidad, sostenibilidad, geoconservación, Indianópolis.

(*) Doutoranda no Programa de Pós-Graduação em Geografia da Universidade Federal de Uberlância - Av. João Naves de Ávila, 2121 - Bloco 1H Sala 16, CEP: 38408-100 ,Uberlândia (MG) - Brasil, Tel.: (+ 55 34) 2345-1512 - liliancmb@yahoo.com.br

(**) Prof. Dr. do Programa de Pós-Graduação em Geografia da Universidade Federal de Uberlância - Av. João Naves de Ávila, 2121 - Bloco 1H Sala 16, CEP: 38408-100,Uberlândia (MG) - Brasil, Tel.: (+ 55 34) 2345-1512 - silgel@ufu.br 


\section{INTRODUÇÃO}

O turismo emerge no século XXI como uma das atividades do setor terciário que mais cresce, cerca de 4,4\% ao ano no Brasil segundo dados da EMBRATUR (2008), representando uma profícua opção de desenvolvimento. Dentre as modalidades e segmentos turísticos existentes, aqueles realizados em áreas naturais, tais como o ecoturismo, o turismo rural, o turismo de aventura e, mais recentemente, o geoturismo têm se destacado na atualidade.

O Brasil é detentor de uma grande extensão de terras, contando com uma variedade de atrativos, inclusive, com uma relevante biodiversidade e geodiversidade que são, respectivamente, a matéria-prima do ecoturismo e do geoturismo.

A região do Triângulo Mineiro/Alto Paranaíba não foge à essa característica brasileira, apresentando ricos exemplares do patrimônio geológico, como grutas, quedas d'água, domos, sítios paleontológicos, entre muitos outros exemplos da geodiversidade local.

Toda essa geodiversidade faz com que esta região tenha grande potencial geoturístico, sendo excelente destino para aquelas pessoas interessadas não só em contemplar a paisagem, mas compreendê-la melhor, seja através de meios interpretativos personalizados ou não-personalizados.

O município de Indianópolis/MG é reconhecido pela diversidade e beleza de suas quedas d'água, característica esta que levou-nos a criar a problemática a qual este trabalho pretendeu responder: qual o potencial das quedas d'água de Indianópolis/MG como locais para a prática do geoturismo?

A justificativa e iniciativa de se identificar as potencialidades das quedas d'água de Indianópolis/ MG vêm da necessidade de se conhecer e registrar a geodiversidade local, oportunizando a criação de recursos de divulgação e valorização que aproxime a sociedade da geodiversidade, fazendo com que ela passe a entendê-la, contribuindo para a sua geoconservação.

Além disso, os segmentos turísticos de base natural, como o geoturismo e o ecoturismo, são considerados uma forma de turismo alternativo, menos impactante que o turismo de massa, podendo ser considerados como

[...] inteligentes instrumentos de viabilização econômica para o gerenciamento correto dos recursos naturais, proporcionando aos brasileiros uma alternativa digna de conquistar seu sustento e uma vida melhor, ao mesmo tempo que assegura às gerações futuras o acesso às heranças da natureza (OLIVEIRA, 2000, p. 48).

Nesse sentido, a implantação do geoturismo em Indianópolis reveste-se de grande importância já que pode gerar renda e empregos para muitas famílias, dinamizando a economia local e regional, sendo forte incentivo para a conservação dos locais onde se encontram as quedas d'água mediante um rigoroso processo de planejamento turístico, uma vez que este "[...] pode e deve converter-se em importante ferramenta para se alcançar a sustentabilidade econômica, sociocultural e ambiental dos locais, em particular de uma região e do país todo" (DIAS, 2003, p. 154).

\section{ÁREA DE ESTUDO}

O município de Indianópolis tem uma área de 833, $870 \mathrm{~km} 2$ e, segundo a Associação Mineira de Municípios, está localizado no Triângulo Mineiro, oeste de Minas Gerais, sendo limítrofe aos municípios de Uberlândia, Araguari, Nova Ponte, Uberaba e Estrela do Sul (IGA, 2009), entre as

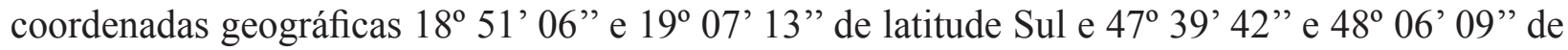
longitude Oeste (figura 1).

\section{METODOLOGIA}

A metodologia é uma forma de ordenamento racional da pesquisa, com a definição de etapas e técnicas, visando facilitar o planejamento, a investigação, a experimentação e a conclusão da 
pesquisa científica. A escolha das técnicas deve variar segundo o tipo de pesquisa que se pretende realizar: básica, aplicada, quantitativa, qualitativa, exploratória, descritiva, experimental, pesquisa-ação, entre outras.

As etapas e técnicas empregadas nesta pesquisa, no intuito de atingir os objetivos propostos, podem ser visualizadas no fluxograma metodológico simplificado exposto na próxima página (figura 2).
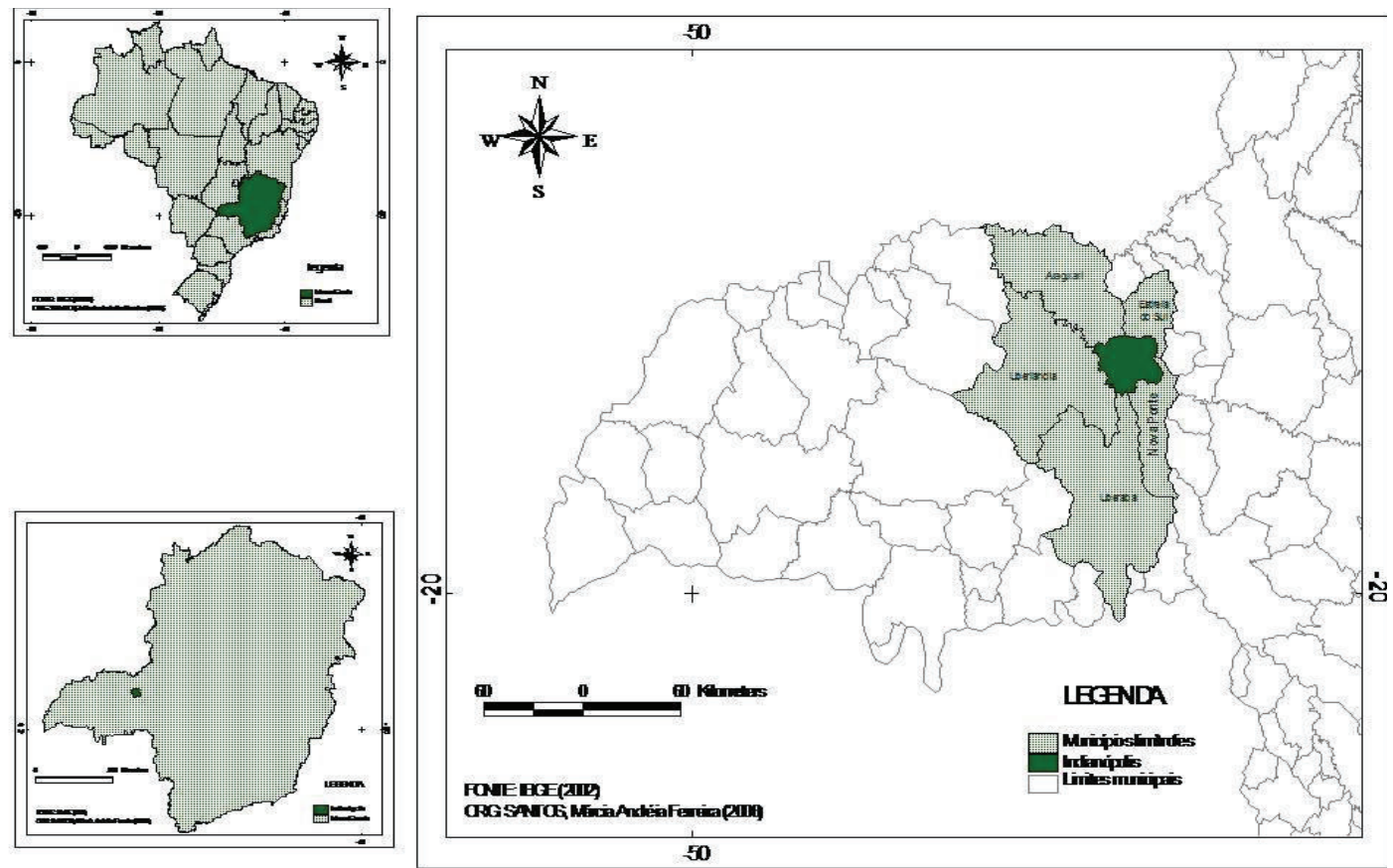

Figura 1 - Localização do município de Indianópolis no contexto do território brasileiro, mineiro e da região do Triângulo Mineiro.

Posteriormente à escolha da área de estudo e da temática a ser trabalhada procedeu-se à fundamentação teórica, momento que possibilitou um diálogo com diversos autores sobre conceitos, explicações, modelos teóricos e metodologias existentes sobre turismo e geoturismo, planejamento turístico, formação e evolução de quedas d'água, entre outros temas afins, situando o estudo no contexto geral da problemática aqui analisada.

Nesta etapa buscou-se também analisar obras que tratassem das características naturais e sócio-econômicas da mesorregião do Triângulo Mineiro/Alto Paranaíba, obtendo informações que permitiu, juntamente com os trabalhos de campo, a caracterização e o entendimento dos aspectos fisiográficos do município de Indianópolis.

Num segundo momento recorreu-se a documentação direta através dos trabalhos de campo na área rural do município de Indianópolis, localizando as quedas d'água e observando também características como vegetação, solo, tipos de rocha, modelado da superfície terrestre além de visitar os proprietários rurais que mantêm casarões com arquitetura centenária e que ainda preservam algumas tradições (tear manual, engenho de tração animal, produção artesanal de mandioca e rapadura etc.), resistindo ao passar do tempo e avanço tecnológico

Nesta etapa coletou-se as coordenadas geográficas de cada queda d'água encontrada com um aparelho de GPS Garmin, procedeu-se à documentação fotográfica, preenchimento de uma planilha com as características locais e também coleta de algumas rochas para serem identificadas em laboratório. Também foi calculada a distância percorrida nas trilhas ecológicas por meio de um aparelho de pedômetro Oregon e a altura das quedas foi identificada manualmente, a partir de uma corda de 100 metros, marcada de $10 \mathrm{em} 10 \mathrm{~m}$ para facilitar a contagem, que era lançada do topo até a base da mesma. 


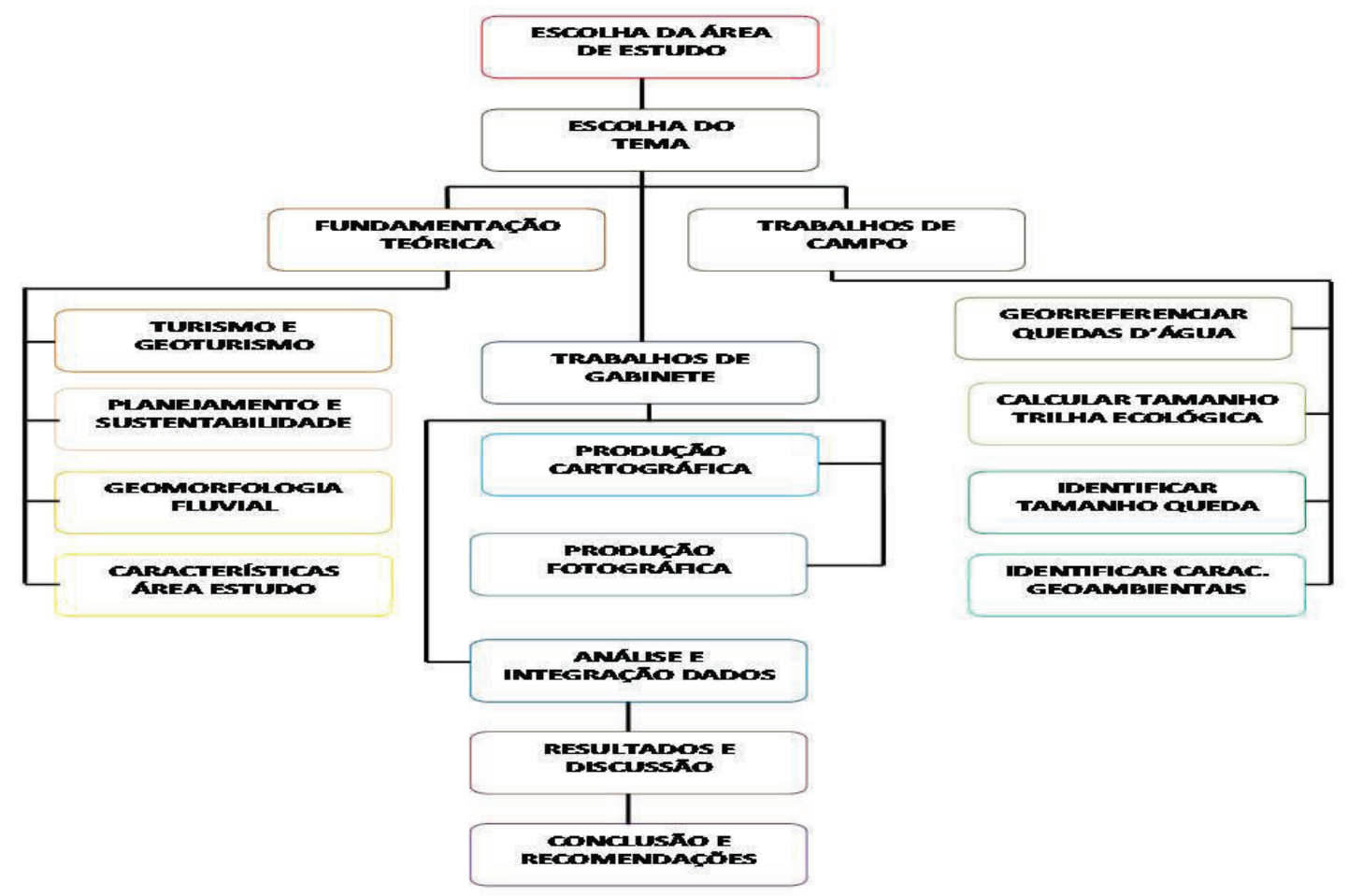

Figura 2 - Fluxograma metodológico simplificado / Org: Bento, 2009.

Já na etapa de integração e análise dos dados, realizada em gabinete, os dados obtidos nas etapas anteriores foram tratados e analisados o que permitiu um conhecimento mais aprofundado e contextualizado da problemática em questão. Ainda nesta etapa ocorreu a confecção de figuras, tabelas e mapas da área de estudo.

Todos os procedimentos comentados anteriormente permitiram que se chegasse aos resultados e conclusão apresentados, parcialmente, ao longo deste artigo e desde já é preciso deixar claro que o assunto não se esgota aqui e que a temática será aprofundada numa outra pesquisa a ser desenvolvida durante o curso de doutorado em Geografia a qual a autora está matriculada.

\section{REFERENCIAL TEÓRICO}

O turismo de natureza engloba todos aqueles segmentos que têm o meio ambiente natural como matéria-prima, entre eles, o ecoturismo e o geoturismo, sendo o tipo de turismo que mais tem se destacado na atualidade.

Existem muitos estudos que trabalham na perspectiva de compreensão dos fatores que levam ao crescimento do turismo natural e, em linhas gerais, destacam-se aspectos relacionados com a qualidade de vida urbana, com a instrução escolar, com aspectos econômicos, espirituais etc.

A demanda crescente pelo turismo e pelos lazeres, especificamente na natureza, é, sem dúvida, uma das tendências mais significativas dos movimentos turísticos na atualidade, talvez como um antídoto para as pressões da vida moderna, potencializado pela velocidade e poder de informação e da mídia, produzindo efeitos nos planos econômico, ecológico e territorial (SANTOS, 2004, p. 10).

A busca por áreas naturais faz expandir o mercado turístico baseado em segmentos como o turismo rural, o turismo de aventura, o ecoturismo e, mais recentemente, o geoturismo. Isto reflete no surgimento de uma nova tendência mundial na qual as pessoas tentam suprir suas deficiências e esquecer seus problemas, tendo contato com um meio ambiente natural sadio, harmônico, autêntico, belo e que lhe provoque sensações de paz, contentamento, pertencimento, direcionamento, 
conhecimento etc., sensações estas, a maioria, perdidas gradualmente com a evolução da sociedade contemporânea.

Dos segmentos turísticos que se baseiam na visitação de áreas naturais o geoturismo é o mais recente, tendo o seu conceito ainda em construção, sendo reelaborado e enriquecido com a contribuição de estudiosos de todo o mundo.

Apesar de incipiente no território brasileiro já existem alguns estudos voltados ao geoturismo, inclusive dissertações e teses, além da realização de eventos que incorporam essa temática na pauta em discussão. O surgimento desse novo segmento turístico, que é por muitos autores considerado um sub-segmento do ecoturismo, está relacionado, em linhas gerais, com a necessidade de entendimento das áreas visitadas por parte dos turistas e com a possibilidade de divulgação e valorização do patrimônio natural abiótico.

O primeiro conceito relacionado ao geoturismo foi criado em 1995 por Thomas Hose, mas o mesmo o redefiniu e aprimorou em 2000, para “[...] a provisão de facilidades interpretativas e serviços para promover os benefícios sociais de lugares e materiais geológicos e geomorfológicos e assegurar sua conservação, para uso de estudantes, turistas e outras pessoas com interesse recreativo ou de lazer" (HOSE, 2000 apud LEITE DO NASCIMENTO; RUCHKYS; MANTESSO-NETO, 2007, p. 5).

O geoturismo está relacionado, portanto, com os recursos naturais muitas vezes negligenciados pelo ecoturismo - aspectos geológicos e geomorfológicos - e pode ter, basicamente, três motivações: recreação, lazer e aprendizado, todos contribuindo para a conservação de atrativos como quedas d'água, cavernas, afloramentos rochosos, serras, vulcões, jazidas de minerais, cânions, entre outros.

Hose não foi o único que definiu geoturismo, após ele surgiram muitos outros estudiosos e instituições nessa empreitada, alguns priorizando os aspectos geológicos, outros os geomorfológicos e ainda outros que ampliaram o seu leque de abrangência.

Para Silva e Perinotto (2007, ñ paginado), o geoturismo

[...] é a atividade do turismo com conotação geológica, ou seja, a visita organizada e orientada a locais onde ocorrem recursos do meio físico geológico que testemunham uma fase do passado ou da história da origem e evolução do planeta Terra. Também se inclui, nesse contexto, o conhecimento científico sobre a gênese da paisagem, os processos envolvidos e os testemunhos registrados em rochas, solos e relevos.

Esta citação vai ao encontro do conceito de Hose, enfatizando os aspectos e processos geológicos e geomorfológicos como recursos turísticos do geoturismo. Nesse sentido, Silberman (1970 apud Aguiar; Dias, 2002), explica que esses recursos podem ser classificados em:

. Litoral: rochas, ilhas, praias, falésias.

. Lagos e lagoas.

. Correntes de água superficial: rios, quedas d'água, corredeiras.

. Correntes de água subterrânea: mananciais, grutas.

. Relevos: planícies, dunas, canyons, montanhas, chapadas.

. Manifestações vulcânicas: crateras, águas termais e minerais, gêiseres etc.

Pereira (2006), explica que essa valorização dos elementos abióticos da natureza pelo geoturismo tem como justificativa que a base geológica é o fator mais importante na modelação da paisagem, além de ser um importante documento que testemunhou e continua testemunhando a história da Terra. 
Leite do Nascimento, Ruchkys e Mantesso-Neto (2008), também trabalham nessa perspectiva de valorização dos aspectos abióticos, argumentando que estes constituem o substrato de todo o planeta e também são eles que testemunham a evolução geológica e geomorfológica do planeta.

Vieira e Cunha (2004), Boivin (1990), Dowling e Newsome (2006), Ruchkys (2007), também veem as feições geomorfológicas e geológicas como atrativos principais do geoturismo, estando implícitos no prefixo geo da palavra geoturismo (Apud LEITE DO NASCIMENTO, RUCHKYS E MANTESSO-NETO, 2008).

Já as instituições TIA - Travel Industry Association of America - e a NGS - National Geographic Society - conceituam o geoturismo mais abrangentemente, estendendo-o à prática turística que privilegia as características geográficas de um lugar, tanto o meio natural como "[...] a cultura, estética, patrimônio e bem-estar dos seus residentes" (STEVE et al, 2002 apud LEITE DO NASCIMENTO; RUCHKYS; MANTESSO NETO, 2007, p. 5).

O conceito acima se aproxima bastante do conceito de ecoturismo, em que a experiência turística não se restringe apenas à questão natural, como envolve também as comunidades locais e suas respectivas tradições e cultura.

Manosso (2007, p. 48) ressalta que apesar desse segmento turístico ser associado aos patrimônios geomorfológico e geológico não deve ficar restrito às feições mais belas, devendo ser entendido como "[...] qualquer visita turística de uma pessoa ou um grupo a um lugar cujo objetivo é apreciar, entender ou se interar com a paisagem".

Nesse sentido, Leite do Nascimento, Schobbenhaus e Medina (2009), explicam que o geoturismo tem por objetivo preencher uma lacuna do ponto de vista da informação, possibilitando ao turista não só contemplar as paisagens, como entender os processos geológicos e geomorfológicos responsáveis por sua formação.

Se os objetivos do geoturismo não são meramente contemplativos e apresentam uma finalidade didática podemos associá-lo à educação ambiental. Esse é o posicionamento de Geremia et al (2004 apud SILVA, 2007, p. 35) que afirmam que o geoturismo "[...] possibilita a interpretação da herança natural da paisagem quando se desfruta e reconhece as suas particularidades geológicas e geomorfológicas".

Reynard e Pralong (2004 apud SILVA, 2007, p. 35), frisam que “[...] a problemática do geoturismo inscreve-se no campo do turismo didático, por constituir uma nova forma que oferece instrumentos de interpretação que permitem dialogar e compreender os sítios visitados ou descobertos".

Leite do Nascimento, Ruchkys e Mantesso-Neto (2008, p. 43), ressaltam a questão da interpretação, argumentando que é ferramenta indispensável para "[...] sensibilizar as pessoas sobre a importância do patrimônio e despertar o desejo de contribuir para sua conservação".

É preciso entender a interpretação ambiental como

[...] uma técnica didática, flexível e moldável às mais diversas situações, que busca esclarecer os fenômenos da natureza para determinado público-alvo, em linguagem adequada e acessível, utilizando os mais variados meios auxiliares para tal. A interpretação procura promover neste público o sentimento de pertinência à natureza, através de sua transformação íntima em relação aos recursos naturais, da sua compreensão e de seu entendimento, na esperança de gerar seu interesse, sua consideração e seu respeito pela natureza e, consequentemente, pela vida (PAGANI et al, 1996 apud DIAS, 2003, p. 79).

A interpretação ambiental é uma das estratégias encontradas pelo geoturismo para atingir seu objetivo inicial de assegurar a conservação de lugares e materiais geológicos e geomorfológicos, como definido por Hose, e pode utilizar meios classificados em personalizados e não personalizados.

Um meio que tem sido comumente utilizado pelo geoturismo em diversas partes do mundo são os painéis interpretativos/explicativos colocados em locais de interesse geológico e que incorporam explicações sobre a localização, história geológica e evolução geomorfológica. Através da visitação de áreas onde os principais atrativos são feições geológicas e geomorfológicas e a interpretação é 
uma das formas de sensibilização do público, o geoturismo acaba por permitir uma integração do turismo com a ciência, principalmente as Ciências da Terra, gerando novas oportunidades

[...] quer para a ciência porque alcança nova audiência, quer para o turismo porque proporciona novas oportunidades para melhorar a experiência dos turistas ao oferecer uma visão diferente da paisagem [...], fazendo com que permaneçam mais tempo numa região e gastem consequentemente mais dinheiro, o que estimula a economia local (MONRO, 2004 apud ARAÚJO, 2005, p. 40).

Barreto (2007, p. 31) também encara o geoturismo como uma ponte entre o turismo e a geologia, haja vista que "[...] esse seria inclusive um dos papéis fundamentais do Geoturismo - ter o grande público como seu principal alvo, despertando o interesse pela Geologia, aguçando a curiosidade nesse ramo das paisagens naturais (...)".

Depreendemos que o geoturismo é um segmento baseado no turismo de natureza que veio complementar o ecoturismo, divulgando e valorizando o patrimônio abiótico da paisagem, como os elementos geológicos e geomorfológicos, buscando sua apreciação, interpretação e geoconservação.

Geoconservação devendo ser entendida como "[...] um ramo de atividade científica que tem como objetivo a caracterização, conservação e gestão do patrimônio geológico e processos naturais associados" (BRILHA, 2005 apud SILVA, PERINOTTO, 2007, ñ paginado). O objetivo da geoconservação é conservar a geodiversidade, principalmente dos patrimônios geológicos com significativa relevância, de forma a manter a evolução natural dos aspectos geológicos e geomorfológicos (SHARPLES, 2002 apud BRILHA, 2005).

"A geoconservação é um dos aspectos mais recentes da conservação da natureza" (GRONGGRIJIP, 2000 apud LEITE DO NASCIMENTO, RUCHKYS, MANTESSO NETO, 2008, p. 21) e é importante a proteção e conservação do patrimônio geológico porque ele:

. é um componente importante do Patrimônio Natural;

. representa uma importante herança cultural, de um caráter que não se repete;

. constitui uma base imprescindível para a formação de cientistas e profissionais;

. constitui um elemento de proteção de recursos estéticos e recreativos;

. serve para estabelecer uma ligação entre a história da Terra e a história dos homens e sua evolução biológica. (GALLEGO, GARCIA, 1996 apud MOREIRA, 2008, p. 76-77).

A conservação dos aspectos geológicos e geomorfológicos tem como aliado o geoturismo, este sendo uma ótima oportunidade de promoção do patrimônio geológico, sensibilizando o público em geral para a importância de sua conservação (LARWOOD, PROSSER, 1998; PATZAK, 2001 apud ARAÚJO, 2005).

Ao proporcionar aos turistas uma visão mais científica do que contemplativa da paisagem, o geoturismo acaba por possibilitar a promoção da geoconservação e esta, por sua vez, é ferramenta indispensável na conservação da geodiversidade mundial, seja ela representada por geossítios ou pelo patrimônio geológico (figura 3).

Existem explicações diversas para a gênese e morfologia das quedas d'água e Bartorelli (1997, p. 135) argumenta que essas explicações devem ser concebidas em conjunto, devendo se analisar "[...] o arcabouço estrutural e a evolução tectônica, a morfologia e os processos erosivos (...)".

Depreende-se que em Indianópolis também é preciso compreender a origem e evolução das quedas d'água de forma integrada, sendo o primeiro passo reconhecer os grandes desníveis topográficos gerados a partir da evolução morfotectônica da região Sudeste ocorrida a partir do Cretáceo, o que reativou antigas falhas e fraturas, direcionando os cursos d'água através de extensos e diversos lineamentos tectônicos. É preciso considerar ainda a erosão vertical iniciada a partir do Cenozóico que também gerou grandes desníveis topográficos. 
Os lineamentos da região Sudeste apresentam direções preferenciais noroeste e nordeste e localmente leste-oeste, já os lineamentos do município de Indianópolis apresentam direção nordeste-sudeste, sendo perpendiculares ao lineamento maior, por onde corre o rio Araguari cujas intersecções delineiam um mosaico de blocos tectônico e direcionam a drenagem fazendo com que ela coincida com as principais zonas de fraturas existentes nas rochas vulcânicas, propiciando o aparecimento de quedas d'água (CORSI, 2003).

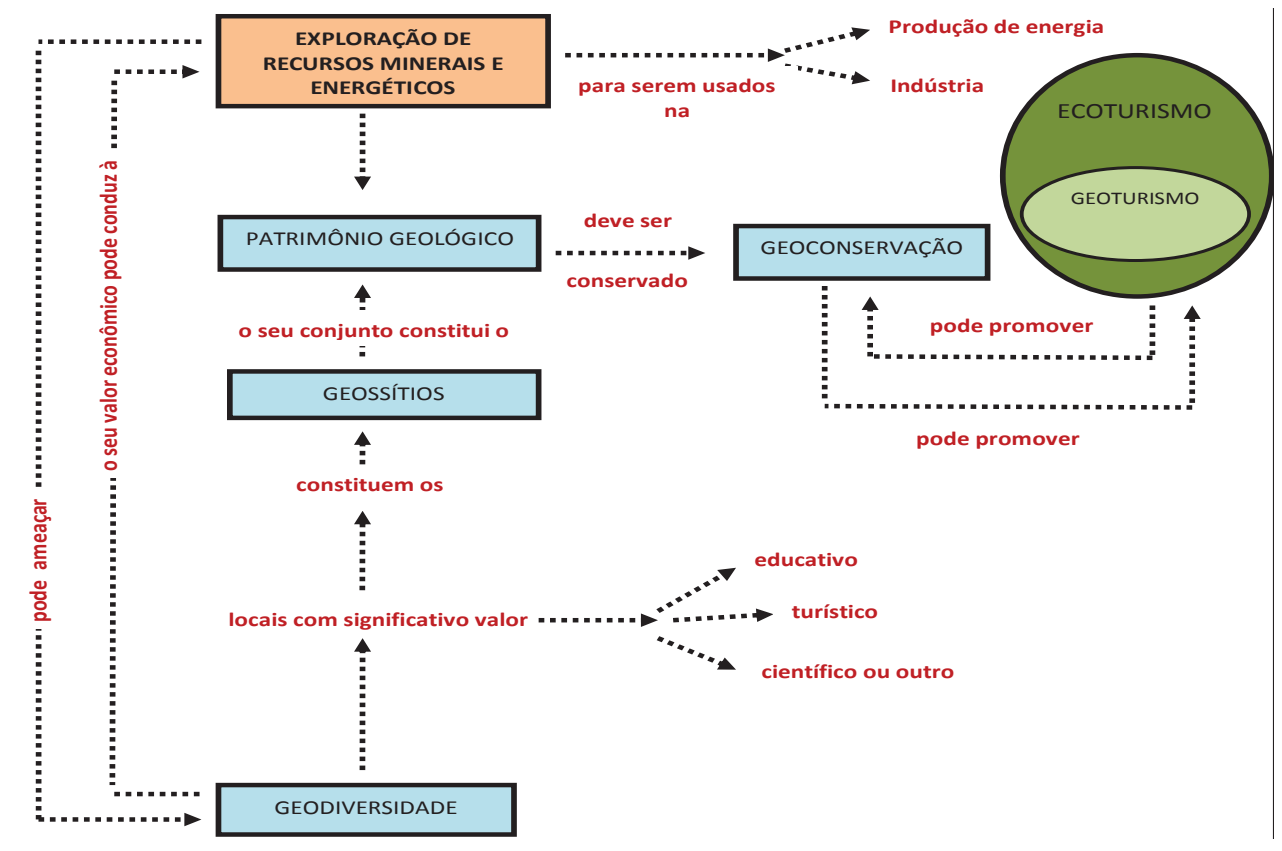

Figura 3 - Esquema das relações entre a Geodiversidade, Geossítios, Patrimônio Geológico, Geoconservação e Geoturismo/Fonte: Adaptado de ARAÚJO, 2005, p. 41.

\section{RESULTADOS E DISCUSSÃO}

Outro elemento relacionado a fenômenos de subsuperfície e que são importantes na formação e morfologia das quedas d'água é a existência de soleiras que fazem a água ganhar mais velocidade ao se concentrar em um só ponto, aumentando seu trabalho erosivo.

A existência de diferentes níveis de fraturamentos no basalto também potencializa a ação erosiva de diversos elementos, como água e raízes, facilitando o desalojamento e desagregação das rochas, tornando-as mais susceptíveis à atuação de outros processos de alteração física e/ou química.

É importante mencionar a influência do potencial erosivo diferencial devido ao contato do basalto com o arenito e devido a descontinuidades observadas dentro do basalto, como é o caso da ocorrência de vesículas e/ou amígdalas.

Tendo como referência os estudos já existentes sobre classificação de quedas d'água e considerando o tamanho da queda e o volume de água foram localizadas vinte quedas na área de estudo, sendo: três saltos, uma cascata, quatro saltinhos (este termo foi criado para designar as quedas que não apresentam o mesmo desnível topográfico dos saltos e que também não são tão largas e volumosas como as cachoeiras) e doze cachoeiras (figura 4).

Em todas estas quedas d'água deparou-se com um rico patrimônio natural abiótico e biótico, fundamentais para o geoturismo e ecoturismo, a primeira expressa através da visualização do perfil da queda com os diferentes contatos litológicos e também do relevo e a segunda, mediante a realização de trilhas ecológicas em locais com formações vegetais, principalmente formações florestais.

As litologias encontradas nas quedas d'água de Indianópolis contam parte da história geológica da região, compreendida entre o Pré-Cambriano e o Mesozóico, eras que estão associadas ao Grupo Araxá (gnaisses) e Grupo São Bento (arenitos e basaltos) - (figura 5), oportunizando ao turista 
um raro momento em que ciência e encanto se encontram, divulgando a riqueza e importância do patrimônio natural abiótico.

Patrimônio é um conceito legal relacionado ao conjunto de bens e direitos de uma pessoa ou instituição, é produto de uma escolha e essa depende do que é considerado como significativo para a sociedade. Nesse sentido, "[...] vão ser os valores atribuídos às coisas e lugares que vão dar um significado a tais coisas e lugares, em relação a outros, e que os transformam em "patrimônio"" (CASTRIOTA, 2004, p. 24).

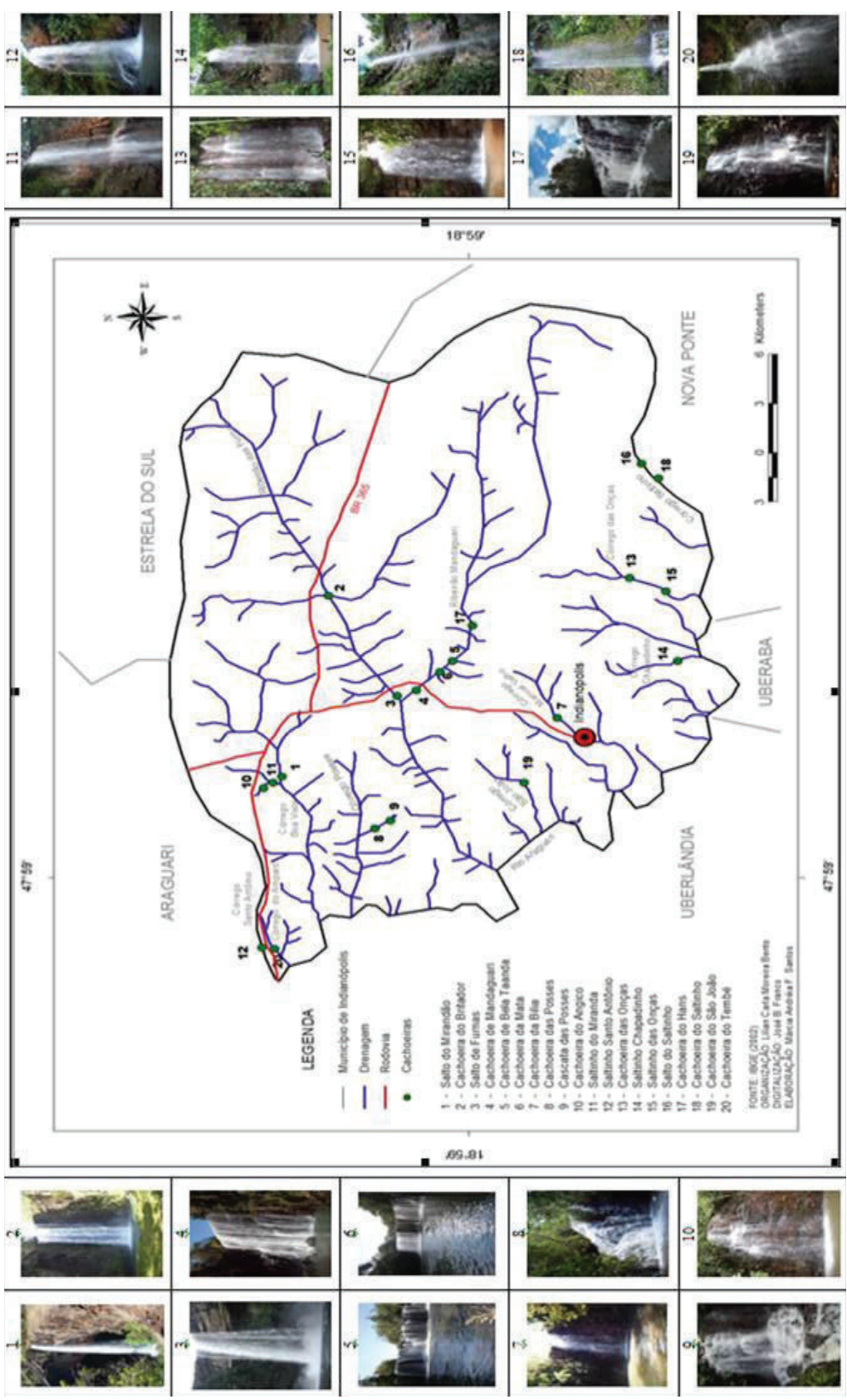

Figura 4 - Mapa de Localização das quedas d'água em Indianópolis.

O processo de patrimonialização tem correlação direta com a preocupação das pessoas em conservar algum aspecto cultural e/ou ambiental e o geoturismo tem essa capacidade de aproximar a sociedade do patrimônio natural abiótico, contribuindo, direta e indiretamente, para a sua divulgação e conservação, como é o caso das quedas d'água do município de Indianópolis.

Considerando o objetivo do geoturismo em unir a contemplação da paisagem com a cientificação do turismo, observou-se fatores como facilidade de acesso, tamanho da queda, beleza cênica, 
presença de poço para banho, diversidade litológica, presença atuante de processos modeladores da paisagem e grau de preservação na tentativa de se selecionar as quedas com maior potencial geoturístico: Salto do Mirandão, Salto de Furnas e Saltinho Santo Antônio.

\begin{tabular}{|c|c|c|c|c|c|}
\hline ERA & GRUPO & FORMAÇĀO & CARACTERÍSTICAS & & \\
\hline 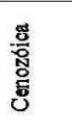 & & 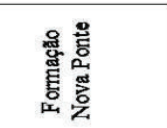 & $\begin{array}{l}\text { Sedimentos } \\
\text { inconsolidados (seixos de } \\
\text { quartzo, quartzitos e } \\
\text { silex). }\end{array}$ & & \\
\hline \multirow[b]{2}{*}{ 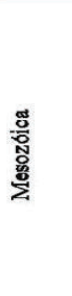 } & \multirow{2}{*}{ 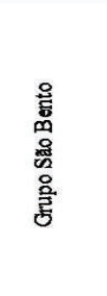 } & 蕗 & $\begin{array}{l}\text { Basaltos originados de } \\
\text { derrames (3-5) com 20 a } \\
150 \mathrm{~m} \text { de espessura, cor } \\
\text { cinza-escuro. }\end{array}$ & & \\
\hline & & 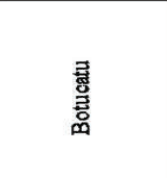 & $\begin{array}{lr}\text { Arenitos } & \text { róseos, } \\
\text { avermelhados } & \text { e } \\
\text { esverdeados, eólicos, com } \\
\text { estratificacōes cruzadas } \\
\text { de pequeno a grande } \\
\text { porte, } \\
\text { silicificados. comumente }\end{array}$ & & \\
\hline 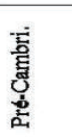 & 总离 & & $\begin{array}{l}\text { Anfibolitos, gnaisses e } \\
\text { micaxistos deformados } \\
\text { pela açấ tectônica } \\
\text { Aparecee nos fundos de } \\
\text { vale. }\end{array}$ & & \\
\hline
\end{tabular}

Figura 5 - Litoestratigrafia do município de Indianópolis. Org.: Bento, autor: Ribeiro, 2009

Ao longo das trilhas que levam a essas quedas com maior potencial os turistas têm oportunidade de admirar e entender não apenas aspectos ligados ao patrimônio natural abiótico, como os tipos de rocha, evolução geológica e processos de esculturação do relevo, como de observar muitos exemplares bem preservados da flora e fauna do Cerrado, o que aponta para uma possível integração do geoturismo com outros segmentos, como o ecoturismo, ampliando e enriquecendo ainda mais a visitação turística (figuras 6,7 e 8 ).
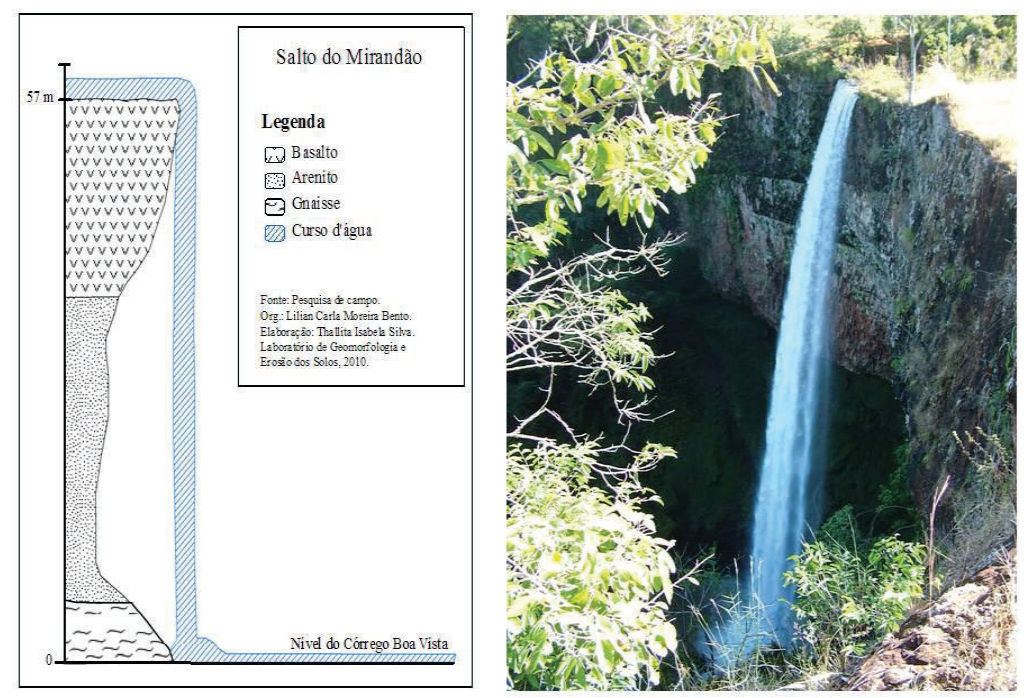

Figura 6 - Perfil litoestratigráfico e fotografia do Salto do Mirandão / Org. e autor: Bento, 2009 - 2010.

Tal realidade vem ao encontro da teoria de Gunn (1988 apud AGUIAR; DIAS, 2002, p. 59), que propõe um aproveitamento integrado dos recursos turísticos já que eles

[...] aparecem, de modo geral, associados em determinado espaço geográfico, embora possa haver predomínio de um deles sobre os demais como principal atrativo para os turistas. Isso é importante como um fator para incrementar a visitação, pois dificilmente haverá lugares que não contem com vários 
recursos utilizáveis e que contribuirão para melhorar a experiência turística, aumentando a estadia e o consumo dos turistas.

Figura 7- Perfil litoestratigráfico e fotografia do Salto de Furnas / Org. e autor: Bento, 2009 - 2010.
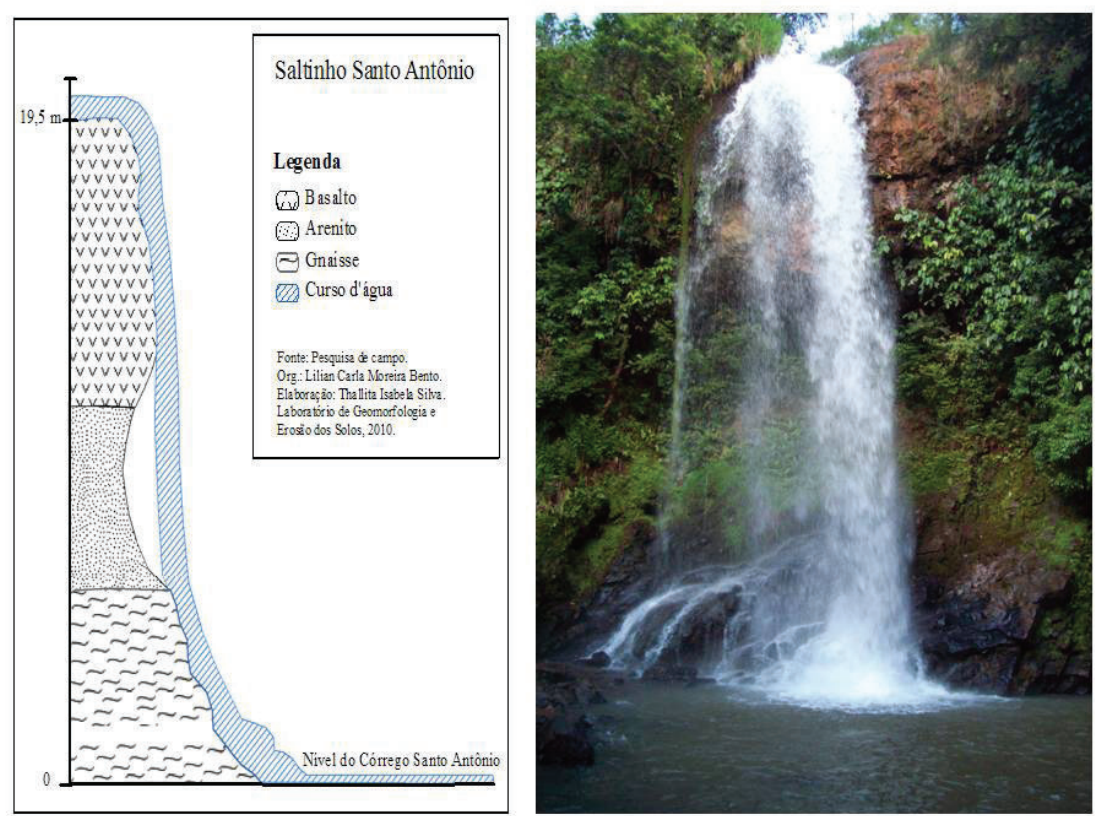

Relevante lembrar que algumas características, como contatos litológicos e tipos de formação vegetal estão associados diretamente com a localização das quedas. Por exemplo, só encontramos o gnaisse do Grupo Araxá em quedas de grande desnível topográfico (Mirandão, Miranda, Saltinho, Furnas e Tembé) ou naquelas bem próximas do rio Araguari (Santo Antônio, Saltinho das Onças e Saltinho Chapadinho) - (quadro 01).
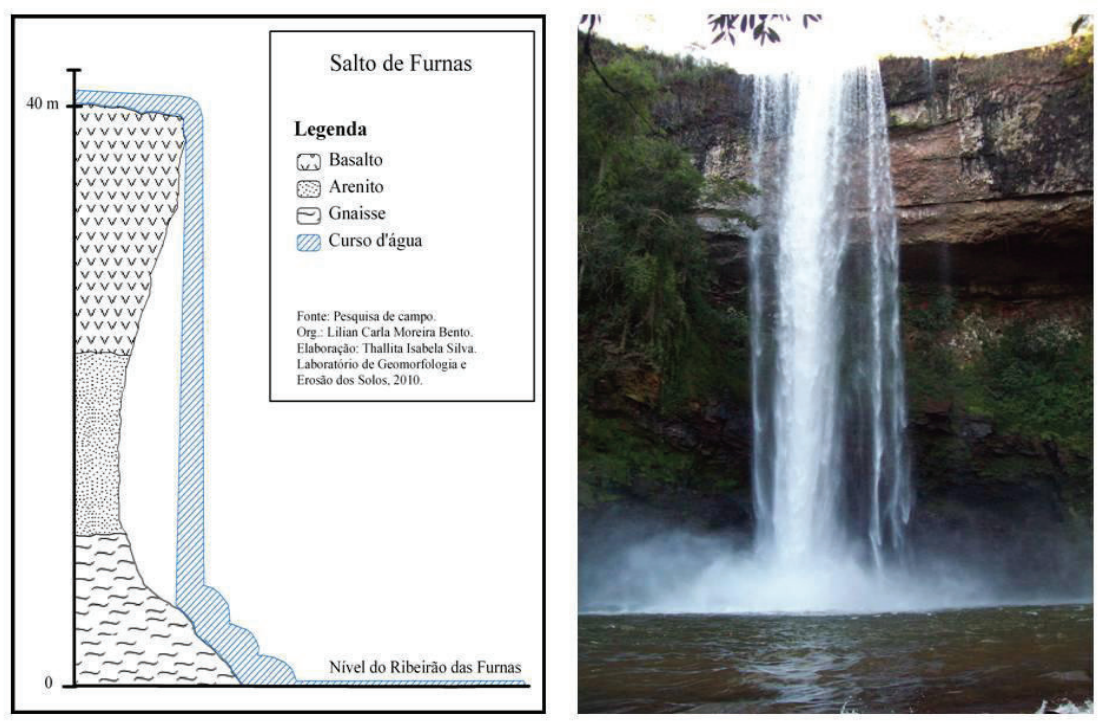

Figura 8 - Perfil litoestratigráfico e fotografia do Saltinho Santo Antônio/ Org. e autor: Bento, 2009 - 2010.

A maioria das formações vegetais encontradas foram: mata seca em locais mais íngremes (Tembé, Saltinho, Mirandão, Miranda, Furnas, Santo Antônio, Cascata das Posses, Mandaguari e Britador), mata ciliar nos córregos mais largos e volumosos, principalmente no Ribeirão Mandaguari 


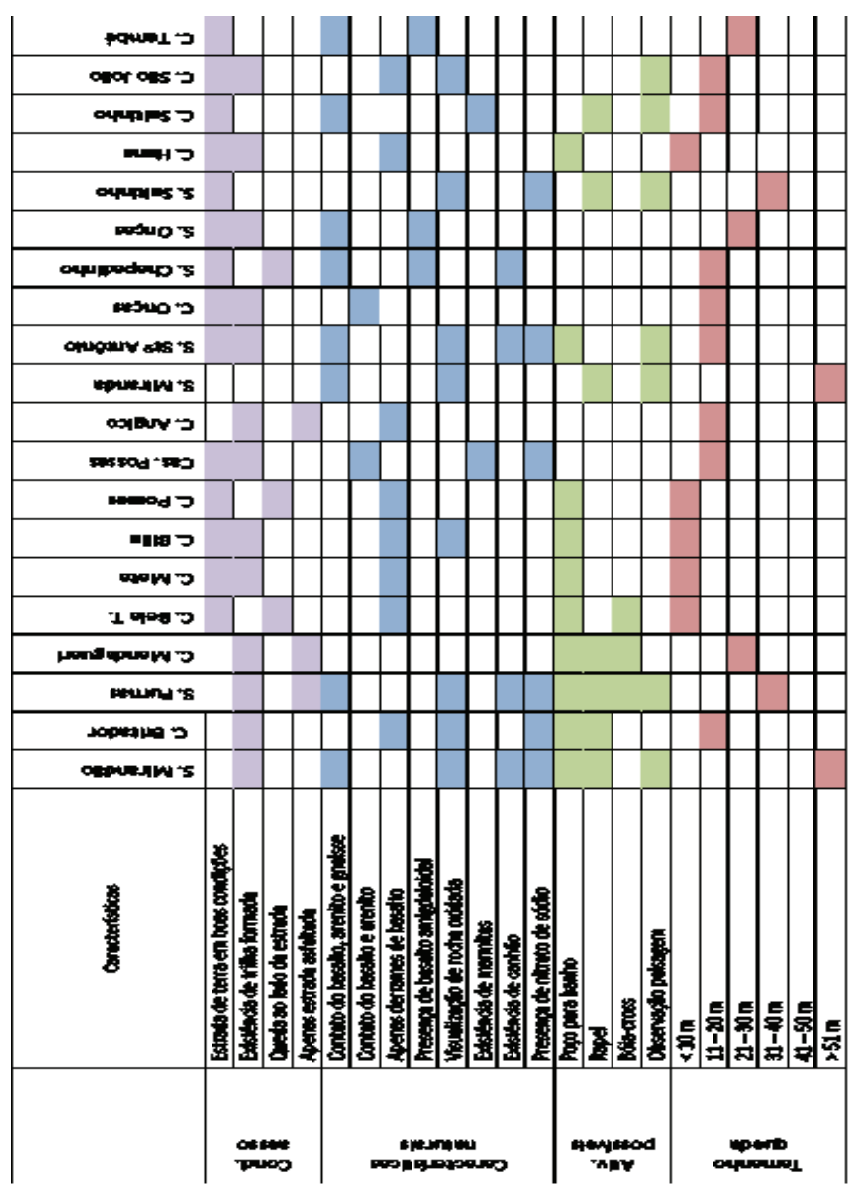

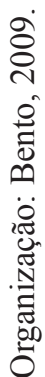


(Bela Taanda, da Mata e Hans), veredas nos topos das chapadas (Hans e Britador) e mata galeria nos córregos mais estreitos e com pouco volume d'água, situação comum no município.

\section{CONSIDERAÇÕES FINAIS}

O geoturismo é um segmento turístico recente que busca a visitação, divulgação e valorização do patrimônio abiótico da paisagem, como quedas d'água, cavernas, cursos d'água, afloramentos rochosos, falésias, entre muitos outros.

Quedas d'água são relevantes atrativos geoturísticos não só pela sua beleza cênica, mas também pela possibilidade de explicação da história geológica através de seu perfil litoestratigráfico, assim como de sua gênese, fazendo com que o turista tenha a oportunidade de aprender um pouco sobre o patrimônio natural abiótico, tornando-se potenciais multiplicadores da importância da geoconservação de locais como estes que são verdadeiras páginas da evolução do planeta Terra.

Através deste trabalho foi possível perceber que as quedas d'água do município de Indianópolis constituem-se em excelentes locais para a prática do geoturismo, permitindo através da identificação de suas diferentes litoestratigrafias remontar milhões de anos, passando do Pré-Cambriano ao Mesozóico, o que possibilita o entendimento de parte da história da geológica da região Sudeste, bem como de sua evolução geomorfológica e identificação de variados agentes erosivos atuantes na gênese e evolução das quedas d'água.

É mister que toda a riqueza de aspectos bióticos e abióticos da natureza encontrados ao longo das quedas d'água de Indianópolis seja conservada e apesar de ainda hoje não existir uma modalidade turística sustentável é possível que o geoturismo atinja o status de atividade sustentável procedendo ao planejamento turístico.

Apenas através do planejamento será possível satisfazer não só as gerações atuais como as futuras, proporcionando o desenvolvimento da atividade turística de forma a não degradar o meio ambiente natural e cultural que usufrui, não interferindo no desenvolvimento de outras atividades e processos e não degradando a qualidade de vida da população local (LADWIG; NUNES, 2004).

Sendo o planejamento ferramenta tão indispensável ao desenvolvimento sustentável da atividade turística cabe ao poder público criar políticas e leis que incentivem a sua realização, disciplinando o desenvolvimento turístico, uma vez que é seu papel determinar e fiscalizar regras para o uso dos recursos naturais mediante planejamento e gestão ambientais (OLIVEIRA, 2004).

\section{AGRADECIMENTOS}

Agradecimentos ao CNPq - Conselho Nacional de Desenvolvimento Científico e Tecnológico pela bolsa de mestrado e a CAPES - Coordenação de Aperfeiçoamento de Pessoal de Nível Superior pela bolsa de doutorado.

\section{REFERÊNCIA BIBLIOGRÁFICA}

AGUIAR, M. R.; DIAS, R. Fundamentos do Turismo. Campinas: Alínea, 2002.

ARAÚJO, E. L. da S. Geoturismo: conceptualização, implementação e exemplo de aplicação ao Vale do Rio Douro no Setor Porto-Pinhão. 2005. 219 f. Dissertação (Mestrado em Ciências do Ambiente) - Escola de Ciências, Universidade do Minho, Minho, 2005.

BARRETO, J. M. C. Potencial geoturístico da região de Rio de Contas - Bahia - Brasil. 2007. 164 f. Dissertação (Mestrado em Geologia) - Instituto de Geociências, Universidade Federal da Bahia, Salvador, 2007. BARTORELLI, A. As grandes cachoeiras da Bacia do Paraná e sua relação com alinhamentos tectônicos. 1997. 190 f. Tese (Doutorado em Geologia) - Instituto de Geociências e Ciências Exatas, Universidade Estadual Paulista, Rio Claro, 1997. 
BRILHA, J. Patrimônio geológico e geoconservação - a conservação da natureza na sua vertente geológica. Braga: Palimage, 2005.

CASTRIOTA, L. B. Patrimônio: conceito e perspectiva. In: BESSA, A. S. M. (Coord.). Preservação do patrimônio cultural: nossas casas e cidades, uma herança para o future. Belo Horizonte: CREA-MG, 2004. p. $10-12$.

CORSI, A. C. Compartimentação morfoestrutural da região do Triângulo Mineiro (MG): aplicado a exploração de recursos hídricos subterrâneos. 2003. 253 f. Tese (Doutorado em Geociências) - Instituto de Geociências e Ciências Exatas, Universidade Estadual Paulista, Rio Claro, 2003. Disponível em: http:// www.athena.biblioteca.unesp.br. Acesso em: mai. 2008.

DIAS, R. Planejamento do turismo. São Paulo: Atlas, 2003.

EMBRATUR. Segmentos turísticos. Brasília: Ministério do Turismo. 2008. 55p. Disponível em: http:// www.turismo.gov.br. Acesso em: abr. 2008.

LADWIG, N. I.; NUNES, M. S. Avaliação das potencialidades do Morro do Forte como local para o desenvolvimento da prática do ecoturismo. Revista Eletrônica de Turismo, [s.1.], v. 3, n. 2, nov. 2004. Disponível em: http://www.presidentekennedy.br/retur.htm. Acesso em: 20 ago. 2007.

LEITE DO NASCIMENTO, M. A.; RUCHYS, U. A. de; MANTESSO NETO, V. Geoturismo: um novo segmento do turismo no Brasil. Global Tourism, [s.1.], v. 3, n. 2, Nov. 2007. Disponível em: http://www. periodicodeturismo.com.br. Acesso em: 01 mar. 2008.

LEITE DO NASCIMENTO, M. A.; RUCHYS, U. A. de; MANTESSO NETO, V. Geodiversidade, geoconservação e geoturismo - trinômio importante para a proteção do patrimônio geológico. São Paulo: Sociedade Brasileira de Geologia, 2008.

LEITE DO NASCIMENTO, M. A.; SCHOBBENHAUS, C.; MEDINA, A. I. de M. Patrimônio geológico: turismo sustentável. In: SILVA, C. R. da (Ed.). Geodiversidade do Brasil - conhecer o passado para entender o presente e prever o futuro. [S.1]: CPRM, 2009. p. 147 - 162.

MANOSSO, F. C. Geoturismo: uma proposta teórico-metodológica a partir de um estudo de caso do município de Apucarana-PR. Caderno Virtual de Turismo, v. 7, n. 2, Rio de Janeiro, 2007. Disponível em: http://www.cvt-rj.net. Acesso em: out. 2008.

MOREIRA, J. C. Patrimônio geológico em Unidades de Conservação: atividades interpretativas, educativas e geoturísticas. 2008. 428 f. Tese (Doutorado em Geografia) - Centro de Filosofia e Ciências Humanas, Universidade Federal de Santa Catarina, Santa Catarina, 2008

OLIVEIRA, J. A. P. A variável socioambiental nos processos de planejamento do setor turístico. In: EMBRATUR. Gestão em turismo e hotelaria: experiências públicas e privadas. São Paulo: Aleph, 2004. p. 21 -36. OLIVEIRA, A. P. O. Turismo e desenvolvimento - planejamento e organização. São Paulo: Atlas, 2000. PEREIRA, P. J. da S. Patrimônio geomorfológico: conceptualização, avaliação e divulgação. Aplicação ao Parque Natural de Montesinho. 2006. 395 f. Tese (Doutorado em Ciências) - Escola de Ciências, Universidade do Minho, Minho, 2006.

SANTOS, A. A. A importância do Circuito Turístico para o fomento da economia e da preservação ambiental - caso São Roque de Minas. 2004. 113 f. Dissertação (Mestrado em Administração), Departamento de Administração, Universidade Federal de Lavras, Lavras, 2004. Disponível em: http://bibtede.ufla. br. Acesso: jan. 2009.

SILVA, F. R. A paisagem do Quadrilátero Ferrífero, MG: Potencial para o uso turístico da sua geologia e geomorfologia. 2007. 144 f. Dissertação (Mestrado em Geografia) - Departamento de Geografia, Universidade Federal de Minas Gerais, Belo Horizonte, 2007. Disponível em: http://www.bibliotecadigital.ufmg. br . Acesso em: 20 ago. 2008.

SILVA, F. R.; PERINOTTO, J. A. de J. O geoturismo na geodiversidade de Paraguaçu Paulista como modelo de geoconservação das estâncias. Global Tourism, [s.1.], v. 3, n. 2, nov. 2007. Disponível em: http://www. periodicodeturismo.com.br . Acesso em: 01 mar. 2008. 